\title{
Effect of laser assisted hatching on outcome of assisted reproductive technology
}

\author{
Amro Elhussieny, Mohamed El Mandouh, Sherif Hanafi, Ghada M. Mansour*, Ahmed El-Kotb
}

Department of Obstetrics and Gynecology, Ain Shams University, Cairo, Egypt

Email:"gmansour@hotmail.com

Received 6 May 2013; revised 7 June 2013; accepted 15 June 2013

Copyright (C) 2013 Amro Elhussieny et al. This is an open access article distributed under the Creative Commons Attribution License, which permits unrestricted use, distribution, and reproduction in any medium, provided the original work is properly cited.

\begin{abstract}
Objective: To determine whether laser-assisted hatching can improve clinical outcome of assisted reproductive techniques in both unselected patients and patients with advanced female age, with recurrent implantation failure, or who are using frozen-thawed embryos. Study design: Prospective randomized study. Patients and methods: 179 consecutive women scheduled for intracytoplasmic sperm injection (ICSI) were randomised to either laser assisted hatching (LAH) or non LAH group. Patients were divided into 94 test and 85 control groups. On the day of embryo transfer, the zona pellucida of the selected embryos in the test group was thinned by using an infrared optical laser system, whereas in the control group they were left intact. Clinical pregnancy rates (CPR) and implantation rates (IR) were estimated. Result(s): Patients that underwent LAH $(n=94)$ had CPR, and IR of $35.1 \%$ and $50 \%$, respectively. Patients that did not undergo LAH $(n=85)$ had lower CPR $(28.2 \%, P=0.324)$ and IR $(33 \%, P=230)$, with no statistically significant difference $P<0.05$. Conclusion: The current study suggested that there is no need for the routine use of laser assisted hatching. However, there is evidence of laser assisted hatching benefit in selected patients
\end{abstract}

Keywords: Laser-Assisted Hatching; Advanced Female Age; Implantation Failures; Embryo Cryopreservation; and Pregnancy Rate

\section{INTRODUCTION}

It has been reported that implantation rate per embryo transfer in IVF/ICSI programs is $10 \%$ to $15 \%$ for day 2 or day 3 transfers and $23 \%$ to $25 \%$ for blastocyst transfers. The ability of an embryo to develop and implant

\footnotetext{
"Corresponding author.
}

primarily relates to the quality of originating gametes and intrinsic characteristics of the embryo, such as its chromosomal constitution and the quality of its cytoplasm [1].

However, some proportions of euploid embryos with full developmental potential fail to implant because of hatching difficulties [2].

Numerous approaches to improve the implantation rate have been proposed and practiced. These include, improving the technique of embryo transfer, improving endometrial receptivity, and improving the capacity of the embryo to implant. Assisted hatching ( $\mathrm{AH}$ ) has been proposed as a method for improving the capacity of the embryos to implant [3].

Assisted hatching involves artificial disruption of the zona pellucida, and a variety of AH techniques have been employed including zona thinning, zona drilling (breaching by forming a hole) and complete removal of the zona, use of chemicals, other mechanical techniques, and the use of lasers [4].

Since the first assisted hatching technique that used a mechanical method, several approaches have been proposed including mechanical incision of the zona [5] chemical zona drilling with acidic medium [6] chemical zona thinning [7], laser-assisted [8] and, more recently, piezo technology [9].

Laser assisted micro dissection of the ZP can be done with high precision and repeatability with no negative impact on in vitro embryo development. The technique is easy to perform and very effective with regard to the overall time requirement and can be performed in a sterile environment without any additional micromanipulations by using the infrared $1.48-\mu \mathrm{m}$ diode laser, it is feasible to open the zona even in largely expanded blasto cysts without visible blastocyst damage. The safety of the 1.48 - $\mu \mathrm{m}$-diode laser beam has been evaluated in mouse and human oocytes and zygotes [10].

Aim of the study was to determine whether laser-assisted hatching can improve clinical outcome of assisted 
reproductive techniques in both unselected patients and patients with advanced female age, with recurrent implantation failure, or who are using frozen-thawed embryos.

\section{SUBJECTS AND METHODS}

The study was carried out over a period of 20 months from December 2010 to August 2012. Ethical approval was granted from the local scientific research committee on August 2010.

On the day of embryo transfer, the patients were randomly selected, starting with a control group that then was followed by a test group. The total number of patients in the control group entered in this study was 94; there were 85 patients in the test group.

These two groups were further subdivided into a total of three subgroups, of patients with advanced female age ( $\geq 35$ y; control, $n=24$; test, $n=30$ ), with implantation failure (for $\geq 1$ cycles; control, $n=42$; test, $n=42$ ), and with frozen-thawed embryos (control, $\mathrm{n}=16$; test, $\mathrm{n}=$ 16). The selected embryos for intrauterine transfer in the patients of the control group were intact, whereas in the test group, they were subjected to laser-assisted hatching (LAH). The latter patients received written information about LAH and were given an opportunity to discuss the method with the embryologist before signing the relevant consent form.

\subsection{Ovarian Stimulation, Oocyte Retrieval, ICSI and Embryo Transfer Cycles}

All of the patients were treated with the same scheme of controlled ovarian stimulation, oocyte retrieval was performed by ultrasound-guided follicle aspiration, 36 - 38 hours after hCG administration under general anesthesia. The oocytes were assessed for maturity and all MII oocytes were subjected to ICSI. Oocytes were examined after 17 - $20 \mathrm{~h}$ to assess fertilization; those with two distinct pronuclei were considered as normal zygotes and transferred into fresh pre-equilibrated P1/10\% HSA. Twenty-five to $27 \mathrm{~h}$ after injection, on day 1 of culture, early cleavage was evaluated and 2-cell embryos were further separated for transfer.

Embryo quality was assessed in all patients according to the following criteria: excellent quality ( $\geq 4$ cells and $<10 \%$ fragmentation), good quality ( $\geq 4$ cells and $10 \%-$ $20 \%$ fragmentation), or poor quality $(<4$ cells and $>20 \%$ fragmentation), and the best quality or good-quality embryos were selected for intrauterine transfer (maximum, 3 to 4 embryos in each embryo transfer cycle.

\subsection{Laser-Assisted Hatching Procedure}

$\mathrm{AH}$ was performed $1 \mathrm{~h}$ before embryo transfer. An Olympus inverted microscope IX-70 $(\times 4,10,20$, and 40 objectives), Fertilase Microsurgical Laser Unit (MMT Medical Technologies) and a display monitor (MMT Medical Technologies, Montreux SA, Switzerland) were used.

The laser was activated five times per embryo in order to thin approximately one-quarter of the circumference of the ZP. The zona was not completely breached. The embryos were then removed from the AH microdrop and placed into a fresh $100-\mu l$ microdrop prior to transfer into the uterus.

\subsection{Embryo Transfer}

The embryo transfer was performed with a Labotect catheter (Labotect, Straberg, Germany), whereas the physician was blinded to the control and test groups. The luteal phase was supported by intravaginal P (Cyclogest 400 , in two divided doses, for a total amount of $800 \mathrm{mg} / \mathrm{d}$; Actavis, Barnstaple, United Kingdom), starting 1 day after oocyte retrieval.

The patients were tested for serum b-hCG assay 15 days after embryo transfer. If the pregnancy test was positive, the patients were followed with serial ultrasound to determine fetal viability. Clinical pregnancy was defined as the presence of a gestational sac on transvaginal ultrasound. When pregnancy occurred, luteal support was continued until 12 weeks' gestation

\subsection{Outcome Measures}

The primary outcome was clinical pregnancy, defined as the presence of fetal heart activity by ultrasound at 6 to 7 weeks' gestation. Secondary outcomes included implantation rates, multiple gestations, and adverse fetal events. Stratified analysis was done using the Mantel-Haenszel chi square test to examine the association between clinical pregnancy and patient group adjusting for other relevant categorical variables (e.g., age category, previous IVF trials, and transfer of frozen embryos).

\section{RESULTS}

A total of 179 patients were consented and enrolled in the study. Two groups are similar in both median age group (31 years) and indication of IVF (Table 1).

Clinical pregnancy was defined as an intrauterine gestational sac and fetal heart motion noted on transvaginal ultrasound 4 weeks after ET, Implantation rate was defined as the number of gestational sacs seen on transvaginal ultrasound 4 weeks after ET divided by the total number of embryos transferred.

The comparison of cycle outcomes for non-hatched and hatched groups is shown in Table 2. Although the clinical pregnancy rate of the hatched group was higher than that of the non-hatched group, $35.1 \%$ versus $28.2 \%$ respectively $(\mathrm{P}=0.32)$ and the implantation rate was 
Table 1. Demographic data, indication for IVF, and protocol used for induction of ovulation in the two study groups.

\begin{tabular}{cccc}
\hline Variable & Group A (n = 85) & Group B (n = 94) & P value \\
\hline Age (yr) & $31(27-35)$ & $31(28-36)$ & 0.226 \\
Age category & & & \\
$<35 \mathrm{yr}$ & $61(71.8 \%)$ & $64(68.1 \%)$ & 0.592 \\
$\geq 35 \mathrm{yr}$ & $24(28.2 \%)$ & $30(31.9 \%)$ & \\
Indication for IVF & & & 0.514 \\
Mixed & $37(43.5 \%)$ & $40(42.6 \%)$ & \\
Tubal factor & $28(32.9 \%)$ & $33(35.1 \%)$ & \\
Male factor & $9(10.6 \%)$ & $4(4.3 \%)$ & \\
Unexplained infertility & $3(3.5 \%)$ & $4(4.3 \%)$ & \\
Sex selection & $8(9.4 \%)$ & $13(13.8 \%)$ & \\
\hline
\end{tabular}

Table 2. Incidence of clinical pregnancy and number of sacs in the two study groups.

\begin{tabular}{cccc}
\hline Variable & Group A (n= 85) & Group B (n= 94) & P value \\
\hline Clinical pregnancy & $24(28.2 \%)$ & $33(35.1 \%)$ & 0.324 \\
Number of sacs & & & \\
No sac & $62(72.9 \%)$ & $60(63.8 \%)$ & 0.294 \\
1 sac & $18(21.2 \%)$ & $23(24.5 \%)$ & \\
2 sacs & $5(5.9 \%)$ & $11(11.7 \%)$ & \\
Implantation rate (\%) & $0(0-33.3)$ & $0(0-50)$ & 0.230 \\
\hline
\end{tabular}

higher in the hatched group than in the non hatched group, 50 versus $33.3 \%$ respectively $(P=0.23)$, the difference was not statistically significant.

Table 3 shows subgroup analysis comparing the two groups in women aged less than 35 years and in women aged 35 years or more at time of treatment. In women who were more than 35 years old, cycles in which LAH was performed were associated with a higher clinical pregnancy rate $(70 \%$ versus $25 \%, \mathrm{P}=0.001)$.

Subgroup analysis compared the two groups in women with or without previous trials is shown in Table 4. In women with 1 trial, cycles in which LAH was performed were associated with statistically significant higher clinical pregnancy $(\mathrm{P}=0.04)$.

Subgroup analysis compared the two groups in women with fresh and frozen embryo transfer. There was no statistically significant difference between the two groups as shown in Table 5.

\section{DISCUSSION}

As the literature indicates, there is still a debate on the role of assisted hatching in ART. Some researchers have
Table 3. Incidence of successful pregnancy in the two study group stratified for age category.

\begin{tabular}{|c|c|c|c|c|c|}
\hline $\begin{array}{c}\text { Age } \\
\text { category }\end{array}$ & $\begin{array}{c}\text { Clinical } \\
\text { pregnancy }\end{array}$ & & $\begin{array}{c}\text { Group A } \\
(\mathbf{n}=\mathbf{8 5})\end{array}$ & $\begin{array}{c}\text { Group B } \\
(n=94)\end{array}$ & P value \\
\hline \multirow[t]{4}{*}{ Age $<35 y r$} & Negative & Count & 43 & 52 & 0.159 \\
\hline & & $\%$ within Group & $70.5 \%$ & $81.3 \%$ & \\
\hline & Positive & Count & 18 & 12 & \\
\hline & & $\%$ within Group & $29.5 \%$ & $18.8 \%$ & \\
\hline \multirow[t]{4}{*}{ Age $\geq 35 y r$} & Negative & Count & 18 & 9 & 0.001 \\
\hline & & $\%$ within Group & $75.0 \%$ & $30.0 \%$ & \\
\hline & Positive & Count & 6 & 21 & \\
\hline & & $\%$ within Group & $25.0 \%$ & $70.0 \%$ & \\
\hline \multirow[t]{4}{*}{ Total } & Negative & Count & 61 & 61 & 0.324 \\
\hline & & $\%$ within Group & $71.8 \%$ & $64.9 \%$ & \\
\hline & Positive & Count & 24 & 33 & \\
\hline & & $\%$ within Group & $28.2 \%$ & $35.1 \%$ & \\
\hline
\end{tabular}

Mantel-Haenszel chi square test

0.479

Table 4. Incidence of successful pregnancy in the two study group stratified for number of previous IVF trials.

\begin{tabular}{|c|c|c|c|c|c|}
\hline $\begin{array}{c}\text { Previous } \\
\text { trials }\end{array}$ & $\begin{array}{c}\text { Clinical } \\
\text { pregnancy }\end{array}$ & & $\begin{array}{c}\text { Group A } \\
(n=85)\end{array}$ & $\begin{array}{c}\text { Group B } \\
(\mathrm{n}=94)\end{array}$ & P value \\
\hline \multirow[t]{4}{*}{ Nil } & Negative & Count & 43 & 52 & 0.140 \\
\hline & & $\%$ within Group & $74.1 \%$ & $78.8 \%$ & \\
\hline & Positive & Count & 15 & 14 & \\
\hline & & $\%$ within Group & $25.9 \%$ & $21.2 \%$ & \\
\hline \multirow[t]{4}{*}{1 trial } & Negative & Count & 9 & 5 & 0.040 \\
\hline & & $\%$ within Group & $69.2 \%$ & $31.3 \%$ & \\
\hline & Positive & Count & 4 & 11 & \\
\hline & & $\%$ within Group & $30.8 \%$ & $68.8 \%$ & \\
\hline \multirow[t]{4}{*}{2 trials } & Negative & Count & 8 & 4 & 0.311 \\
\hline & & $\%$ within Group & $72.7 \%$ & $57.1 \%$ & \\
\hline & Positive & Count & 3 & 3 & \\
\hline & & $\%$ within Group & $27.3 \%$ & $42.9 \%$ & \\
\hline \multirow[t]{4}{*}{3 trials } & Negative & Count & 1 & 0 & 0.286 \\
\hline & & $\%$ within Group & $50.0 \%$ & $0.0 \%$ & \\
\hline & Positive & Count & 1 & 5 & \\
\hline & & $\%$ within Group & $50.0 \%$ & $100.0 \%$ & \\
\hline \multirow[t]{4}{*}{ Total } & Negative & Count & 61 & 61 & 0.079 \\
\hline & & $\%$ within Group & $71.8 \%$ & $64.9 \%$ & \\
\hline & Positive & Count & 24 & 33 & \\
\hline & & $\%$ within Group & $28.2 \%$ & $35.1 \%$ & \\
\hline
\end{tabular}


Table 5. Incidence of successful pregnancy in the two-study group stratified for type of embryo transfer.

\begin{tabular}{|c|c|c|c|c|c|}
\hline $\begin{array}{c}\text { Type of embryo } \\
\text { transfer }\end{array}$ & $\begin{array}{l}\text { Clinical } \\
\text { pregnancy }\end{array}$ & & $\begin{array}{c}\text { Group A } \\
(n=85)\end{array}$ & $\begin{array}{c}\text { Group B } \\
(n=94)\end{array}$ & P value \\
\hline \multirow[t]{4}{*}{$\begin{array}{l}\text { Fresh embryo } \\
\text { transfer }\end{array}$} & Negative & Count & 54 & 55 & 0.086 \\
\hline & & $\begin{array}{l}\text { \% within } \\
\text { Group }\end{array}$ & $78.3 \%$ & $70.5 \%$ & \\
\hline & Positive & Count & 15 & 23 & \\
\hline & & $\begin{array}{l}\text { \% within } \\
\text { Group }\end{array}$ & $21.7 \%$ & $29.5 \%$ & \\
\hline \multirow[t]{4}{*}{$\begin{array}{c}\text { Frozen embryo } \\
\text { transfer }\end{array}$} & Negative & Count & 7 & 6 & 0.264 \\
\hline & & $\begin{array}{l}\text { \% within } \\
\text { Group }\end{array}$ & $43.8 \%$ & $37.5 \%$ & \\
\hline & Positive & Count & 9 & 10 & \\
\hline & & $\begin{array}{l}\text { \% within } \\
\text { Group }\end{array}$ & $56.3 \%$ & $62.5 \%$ & \\
\hline \multirow[t]{4}{*}{ Total } & Negative & Count & 61 & 61 & 0.079 \\
\hline & & $\begin{array}{l}\text { \% within } \\
\text { Group }\end{array}$ & $71.8 \%$ & $64.9 \%$ & \\
\hline & Positive & Count & 24 & 33 & \\
\hline & & $\begin{array}{l}\text { \% within } \\
\text { Group }\end{array}$ & $28.2 \%$ & $35.1 \%$ & \\
\hline
\end{tabular}

Mantel-Haenszel chi square test

0.346

tried to introduce assisted hatching as a routine strategy in ART, whereas others are uncertain [11] .

These contradictions may be attributed to the type of $\mathrm{AH}$; the selected patients, the extent of ZP microdissection, or the quality and stage of embryos selected for $\mathrm{AH}$ procedure.

In the present study, we did not compare the different methods of ZP micro dissection, but with the use of laser $\mathrm{ZP}$ thinning, our results in patients with advanced female age or recurrent implantation failure are comparable with those of investigators who applied laser ZP opening and found better results. However, these findings suggest that instead of different methods of LAH, other factors, such as embryo quality and ZP condition, may still be involved in the clinical outcome of LAH.

The current study will focus on the impact of LAH on pregnancy rate, clinical pregnancy rate and implantation rate and whether routine use of LAH is beneficial of we should restrict it to patients with poor prognosis: advanced maternal age, previous implantation failure or frozen embryo transfer.

Few studies have investigated $\mathrm{AH}$ among patients with a relatively good prognosis. Studies of unselected populations suggest that the benefits of AH may not be universal. Antinori et al. reported significant improvement in implantation and pregnancy among patients undergoing their first IVF cycle [12]. Cohen et al. failed to demonstrate a significant benefit of nonselective $\mathrm{AH}$ in a randomized study of patients with normal day 3 basal FSH levels [13].

In our study Patients that underwent LAH $(\mathrm{n}=94)$ had CPR, and IR of $35.1 \%$ and $50 \%$, respectively. In contrast, those patients that did not undergo LAH $(\mathrm{n}=85)$ had lower CPR $(28.2 \%, \mathrm{P}=0.324)$ and $\mathrm{IR}(33 \%, \mathrm{P}=230)$. Although CPR and IR were higher in those patients that underwent $\mathrm{AH}$ than in those that did not, the difference did not reach statistical significance.

A similar result with our study was obtained by Hurst et al., which was conducted on an unselected good prognosis patient population. That study reported a pregnancy rate of $43 \%$ for the hatching group and $23 \%$ for the control group [14]. Likewise randomized trials without any selection, reported no differences in implantation and pregnancy rates between treatment and control groups [15].

The current study showed subgroup analysis compared the two groups as regard female age, in women who were more than 35 years old; cycles in which LAH was performed were associated with higher pregnancy rate ( $70 \%$ versus $25 \% . \mathrm{P}=0.001)$.

This is constant with Schoolcraft et al. who observed that $\mathrm{AH}$ dramatically increases the implantation and pregnancy rates in patients $>40$ years of age [16]. Also, Meldrum et al. reported that the implantation rate increased with $\mathrm{AH}$ in patients 35 to 42 years of age, with the same incidence of spontaneous abortion or of monozygotic twins [17].

On the other hand, Horng et al. revealed that LAH is of no benefit in women $\geq 37$ years of age. The pregnancy and implantation rates after LAH in the older women were lower than those in the control group, but these differences were not statistically significant. These findings were similar to those of Bider et al., who performed mechanical $\mathrm{AH}$ in a selected group of patients who were $\geq 38$ years of age and did not identify an increase in take-home baby rate after IVF treatment [18].

With respect to previous implantation failure(s), the present study shows subgroup analysis compared the two groups in women with or without previous trials. In women with 1 trial, cycles in which LAH was performed were associated with statistically significant higher clinical pregnancy ( $68.8 \%$ vs. $30.8 \%$ respectively $\mathrm{P}=0.04$ ).

With respect to recurrent implantation failure, our data also revealed that LAH is of no benefit in patients with recurrent implantation failure (for $\geq 2$ cycles). The pregnancy and implantation rates after LAH in women with repeated failure for at least two cycles were higher than those in the control group, but these differences were not statistically significant.

The findings were similar to those of Edirisinghe et al. [19], but were in disagreement with two meta-analyses of different methods of AH by Edi-Osagie et al. and Sallam 
et al. that showed a positive trend for patients with repeated implantation failure [20-22].

With respect to frozen-thawed embryos, our data revealed that the implantation and pregnancy rates were higher in the group in which frozen-thawed embryos were undergoing LAH before transfer, as compared with those in the control group, however it was not statistically significant $(62.5 \%$ vs. $29.5 \%$ respectively $\mathrm{P}=$ 0.079 ).

Considering our data and to overcome zona hardening, we suggest that LAH could be performed as a routine strategy in frozen-thawed embryos before they are transferred.

This was similar to Mojtaba et al. who revealed that the implantation and pregnancy rates were significantly higher in the group in which frozen-thawed embryos were undergoing LAH before transfer, as compared with those in the control group [22].

\section{CONCLUSIONS}

This study suggests that there is no need for the routine use of laser assisted hatching. However, there is evidence of laser assisted hatching benefit in certain circumstances such as in patients with a poor prognosis, including those with one or more failed IVF cycles, poor embryo quality and older women more than 35 years of age.

However, more specific studies should be conducted on different subgroup of patients using different assisted hatching methods (such as partial or total) in order to define a selective group, which may benefit better from the procedure.

Proper selection of the candidates for Laser AH is of outmost importance. There is strong evidence supporting that Laser $\mathrm{AH}$ is considered the best technique now as regard safety and efficacy.

\section{REFERENCES}

[1] Huisman, G.J., Fauser, B.C., Eijkemans, M.J. and Pieters, M.H. (2000) Implantation rates after in vitro fertilization and transfer of a maximum of two embryos that have undergone three to five days in culture. Fertility and Sterilit, 73, 117-122. doi:10.1016/S0015-0282(99)00458-6

[2] Fong, C.Y., Bongso, A., Sathananthan, H., Ho, J. and Ng, S.C. (2001) Ultrastructural observations of enzymatically treated human blastocysts: Zona-free blastocyst transfer and rescue of blastocysts with hatching difficulties. $\mathrm{Hu}$ man Reproduct, 16, 540-546.

doi:10.1093/humrep/16.3.540

[3] Cohen, J., Alikani, M., Trowbridge, J. and Rosenwaks, Z. (1992) Implantation enhancement by selective assisted hatching using zona drilling of human embryos with poor prognosis. Human Reproduct, 7, 685-691.

[4] Valojerdi, M., Eftekhari-Yazdi, P., Karimian, L., Hassani, F. and Movaghar, B. (2010) Effect of laser zona thinning on vitrified-warmed embryo transfer at the cleavage stage: A prospective, randomized study. Reproductive BioMedicine Online, 20, 234-242. doi:10.1016/j.rbmo.2009.11.002

[5] Malter, H.E. and Cohen, J. (1989) Blastocyst formation and hatching in vitro following zona drilling of mouse and human embryos. Gamete Research, 24, 67-80. doi: $10.1002 / \mathrm{mrd} .1120240110$

[6] Cohen, J. (1991) Assisted hatching of human embryos. Journal of in Vitro Fertilization and Embryo Transfer, 8 , 179-190. doi:10.1007/BF01130802

[7] Khalifa, E.A.M., Tucker, M.J. and Hunt, P. (1992) Cruciate thinning of the zona pellucida for more successful enhancement of blastocyst hatching in the mouse. Human Reproduct, 7, 532-536.

[8] Hirotoshi, M., Hidehiko, M., Noriko, F., Junko, M., Azusa, K. and Tatsuhiro, T. (2010) Relevance of the site of assisted hatching in thawed human blastocysts: A preliminary report. Fertility and Sterility, 94, 2444-2447.

[9] Nakayama, T., Fujiwara, H., Yamada, S., Tastumi, K., Honda, T. and Fujii, S. (1999) Clinical application of a new assisted hatching method using a piezo-micromanipulator for morphologically low-quality embryos in poor-prognosis infertile patients. Fertility and Sterility, 71, 1014-1018. doi:10.1016/S0015-0282(99)00131-4

[10] Huai, L., Avner, H., Gerald, M. and Matthew, A. (2009) A retroprospective study comparing three different assisted hatching techniques. Fertility and Sterility, 91, 1323-1325. doi:10.1016/j.fertnstert.2008.02.133

[11] Graham, M.C., Hoeger, K.M. and Phipps, W.R. (2000) Initial IVF-ET experience with assisted hatching performed 3 days after retrieval followed by day 5 embryo transfer. Fertility and Sterilit, 74, 668-671. doi:10.1016/S0015-0282(00)01528-4

[12] Antinori, S., Panci, C., Selman, H.A., Caffa, B., Dani, G. and Versaci, C. (1996) Zona thinning with the use of laser: A new approach to assisted hatching in humans. Human Reproduct, 11, 590-594. doi:10.1093/HUMREP/11.3.590

[13] Cohen, J., Alikani, M., Trowbridge, J. and Rosenwaks, Z. (1992) Implantation enhancement by selective assisted hatching using zona drilling of human embryos with poor prognosis. Human Reproduct, 7, 685-691.

[14] Hurst, B., Tucker, M., Awoniyi, A. and Schlaff, W. (1998) Assisted hatching does not enhance IVF success in good prognosis patients. Journal of Assisted Reproduction and Genetics, 15, 62-64. doi:10.1007/BF02766826

[15] Sagoskin, A., Levy, M., Tucker, M., Richter, K. and Widra, E. (2007) Laser assisted hatching in good prognosis patients undergoing in vitro fertilization-embryo transfer: A randomized controlled trial. Fertility and Sterility, 87, 283-287. doi:10.1016/j.fertnstert.2006.07.1498

[16] Schoolcraft, W.B., Schlenker, T., Jones, G.S. and Jones Jr., H.W. (1995) In vitro fertilization in women age 40 and older: The impact of assisted hatching. Journal of Assisted Reproduction and Genetics, 12, 581-584. doi:10.1007/BF02212578

[17] Meldrum, D.R., Wisot, A., Yee, B., Garzo, G., Yeo, L. 
and Hamilton, F. (1998) Assisted hatching reduces the age-related decline in IVF outcome in women younger than age 43 without increasing miscarriage or monozygotic twinning. Journal of Assisted Reproduction and Genetics, 15, 418-421. doi:10.1007/BF02744934

[18] Bider, D., Livshits, A., Yonish, M., Yemini, Z., Mashiach, S. and Dor, J. (1997) Assisted hatching by zona drilling of human embryos in women of advanced age. Human Reproduct, 12, 317-320. doi:10.1093/humrep/12.2.317

[19] Edirisinghe, W.R., Ahnonkitpanit, V., Promviengchai, S., Suwanjanakorn, S., Pruksananonda, K., Chinpilas, V., et al. (1999) A study failing to determine significant benefits from assisted hatching: Patients selected for advanced age, zonal thickness of embryos, and previous failed attempts. Journal of Assisted Reproduction and Genetics, 16, 294-301. doi:10.1023/A:1020497714495
[20] Edi-Osagie, E., Hooper, L. and Seif, M.W. (2003) The impact of assisted hatching on live birth rates and outcomes of assisted conception: A systematic review. $\mathrm{Hu}$ man Reproduction, 18, 1828-1835. doi:10.1093/humrep/deg334

[21] Sallam, H.N., Sadek, S.S. and Agameya, A.F. (2003) Assisted hatching - A meta-analysis of randomized controlled trials. Journal of Assisted Reproduction and Genetics, 20, 332-342. doi:10.1023/A:1024865725713

[22] M.R. Valojerdi, P. Eftekhari-Yazdi, L. Karimian and S.K. Ashtiani, (2008) Effect of laser zona pellucida opening on clinical outcome of assisted reproduction technology in patients with advanced female age, recurrent implantation failure, or frozen-thawed embryos. Fertility and Sterility, 90, 84-91. doi:10.1016/i.fertnstert.2007.06.005 